\title{
Spatial variation in annual actual evapotranspiration of terrestrial ecosystems in China: Results from eddy covariance measurements
}

ZHENG Han 1,2,3 , 'YU Guirui ${ }^{1}$, WANG Qiufeng ${ }^{1}$, ZHU Xianjin ${ }^{1}$, HE Honglin', WANG Yanfen ${ }^{3}$, ZHANG Junhui ${ }^{4}$, LI Yingnian ${ }^{5}$, ZHAO Liang ${ }^{5}$, ZHAO Fenghua ${ }^{1}$, SHI Peili ${ }^{1}$, WANG Huimin ${ }^{1}$, YAN Junhua ${ }^{6}$, ZHANG Yiping ${ }^{7}$

1. Synthesis Research Center of Chinese Ecosystem Research Network, Key Laboratory of Ecosystem Network Observation and Modeling, Institute of Geographic Sciences and Natural Resources Research, CAS, Beijing 100101, China;

2. State Key Laboratory of Loess and Quaternary Geology, Institute of Earth Environment, CAS, Xi'an 710061, China;

3. University of Chinese Academy of Sciences, Beijing 100049, China;

4. Institute of Applied Ecology, CAS, Shenyang 110016, China;

5. Northwest Institute of Plateau Biology, CAS, Xining 810001, China;

6. South China Botanical Garden, CAS, Guangzhou 510650, China;

7. Key Lab of Tropical Forest Ecology, Xishuangbanna Tropical Botanical Garden, CAS, Menglun 666303, Yunnan, China

\begin{abstract}
Understanding the spatial variation in annual actual evapotranspiration (AET) and its influencing factors is crucial for a better understanding of hydrological processes and water resources management. By synthesizing ecosystem-level observations of eddy-covariance flux sites in China (a total of 61 sites), we constructed the most complete AET dataset in China up to now. Based on this dataset, we quantified the statistic characteristics of AET and water budgets (defined as the ratio of AET to annual mean precipitation (MAP), AET/MAP) of terrestrial ecosystems in China. Results showed that AET differed significantly among both different vegetation types and climate types in China, with overall mean AET of $534.7 \pm 232.8$ $\mathrm{mm} \mathrm{yr}^{-1}$. AET/MAP also differed significantly among different climate types, but there were no distinct differences in AET/MAP values across vegetation types, with mean AET/MAP of $0.82 \pm 0.28$ for non-irrigated ecosystems. We further investigated how the main climatic factors and vegetation attributes control the spatial variation in AET. Our findings revealed that the spatial variation of AET in China was closely correlated with the geographical patterns of climate and vegetation, in which the effects of total annual net radiation $\left(R_{n}\right)$, MAP and mean annual air temperature (MAT) were dominant. Thus, we proposed an empirical equation to describe the spatial patterns of AET in China, which could explain about $84 \%$ of the spatial variation in AET of terrestrial ecosystems in China. Based on the constructed dataset, we also evaluated the uncertainties of five published global evapotranspiration products in simulating
\end{abstract}

Received: 2015-09-15 Accepted: 2016-03-11

Foundation: National Natural Science Foundation of China, No.31290221, No.31420103917

Author: Zheng Han (1988-), PhD, specialized in ecosystem ecology. E-mail: zhenghanmarch@sina.com

"Corresponding author: Yu Guirui (1959-), PhD and Professor, E-mail: yugr@igsnrr.ac.cn 
site-specific AET in China. Results showed that large biases in site-specific AET values existed for all five global evapotranspiration products, which indicated that it is necessary to involve more observation data of China in their parameterization or validation, while our AET dataset would provide a data source for it.

Keywords: evapotranspiration; water budget; spatial variation; eddy covariance; terrestrial ecosystem; ChinaFLUX

\section{Introduction}

Evapotranspiration (ET) is the major component for both terrestrial water cycle and surface energy balance (Wang and Dickinson, 2012). Understanding the spatial variation in annual actual evapotranspiration (AET) and its influencing factors is not only crucial for predicting responses of large-scale hydrological processes to global climate change, but also essential for the water resources management (Allen et al., 1998; Dodds et al., 2005; Zhao and Zhao, 2014) and eco-environment researches such as desertification (Zhou et al., 2002) and droughts (McVicar and Jupp, 1998) under climate change.

In recent years, several studies have quantified the spatial patterns of AET at regional (e.g., Li et al., 2014; Liu et al., 2013a; Wang et al., 2013) and global scales (e.g., Mu et al., 2011; Yan et al., 2012; Yuan et al., 2010) using process-based or remote sensing models. Although the spatial patterns described by different models generally agreed well with each other for a given region (Mueller et al., 2011; Liu et al., 2013a), large obvious uncertainties in AET values still remain. For example, the mean AET in China estimated by Boreal Ecosystem Productivity Simulator (BEPS) model (369.8 $\mathrm{mm} \mathrm{yr}^{-1}$ ) (Liu et al., 2013a) was approximately $26 \%$ smaller than the value estimated by Remote Sensing-Penman Monteith model (500 $\mathrm{mm} \mathrm{yr}^{-1}$ ) (Li et al., 2014). The global mean AET differed even more largely among 15 simulations modeled in the Global Soil Wetness Project-2, ranging from 272 to $441 \mathrm{~mm} \mathrm{yr}^{-1}$ (Dirmeyer et al., 2006). These uncertainties may result from the complexity in modeling ET and the lack of its direct observations as well. Thus, in order to reduce the uncertainties in regional AET assessment, it will be necessary to analyze the spatial variation in AET and its influencing factors based on large-scale network measurements of ET across sites and ecosystem types, and thus to discuss the spatial patterns of AET by directly translating ET observations from sites to the regional scale.

A number of in situ observation methods have been widely applied at ecosystem level (Shuttleworth, 2007; Shuttleworth, 2008; Wang and Dickinson, 2012), in which eddy covariance (EC) method can directly measure ET on a continuous and long-term basis (Baldocchi et al., 2001; Yu and Sun, 2006; Baldocchi, 2008; Zhu et al., 2012) and is preferred among meteorologists and ecologists. Currently, with EC as the main observation method, FLUXNET and several regional networks, including regional networks in Europe (CarboEuroflux), North America (Ameriflux) and China (ChinaFLUX) (Baldocchi et al., 2001), have been operating for several years, which provide vital data sources for analyzing spatial variation in AET.

Accurately quantifying the spatial variation in AET would provide a theoretical basis and reference information for the water management and eco-environmental construction in China, since China is a country suffering from severe arid and regional imbalance of water resources. Meanwhile, the complex and diverse climate and vegetation conditions in China 
provide an ideal opportunity to examine the influencing factors of spatial variation in AET, which would also improve our understanding on the global water cycle. Moreover, China has utilized EC method to measure AET of major ecosystem types in key regions since 2002 (Yu et al., 2006) and data from over 50 sites have been collected (Yu et al., 2013), which enables our analysis of spatial patterns of AET in China.

The spatial patterns of AET have been analyzed using water flux measurements collected by EC method in China (Xiao et al., 2013) and Canada (Brümmer et al., 2012), and they concluded that the spatial patterns of AET were mainly affected by mean annual precipitation (MAP), mean annual air temperature (MAT) and vegetation type. As we know, the physical ET process is influenced by various interconnected environmental and biological factors (Jarvis and McNaughton, 1986; Wilson and Baldocchi, 2000; Wang and Dickinson, 2012). Thus, the spatial variation in AET was supposed to be constrained by both climatic factors and vegetation attributes but maybe with different ways. However, current studies still stagnate at single influencing-factor (e.g., MAP and MAT) analysis. As the roles of different climatic factors and vegetation attributes in regulating the spatial patterns of AET are still not known clearly yet, therefore further studies will be needed if a more understanding of the spatial variation in AET and its underlying mechanisms is desired.

Therefore, by synthesizing the eddy covariance flux data in China, we constructed the most complete AET dataset in China up to now. Based on this dataset, we (1) quantified the statistic characteristics of AET and water budgets (defined as the ratio of AET to MAP, AET/ MAP) in terrestrial ecosystems of China, (2) explored how the main climatic factors and vegetation attributes control the spatial variation in AET and thus proposed an empirical equation to describe the spatial patterns of AET in terrestrial ecosystems of China, and then (3) examined the uncertainties of five published global ET products in evaluating AET values in China.

\section{Materials and methods}

\subsection{Sites used in this study}

In this study, we collected water flux data from two sources, i.e., the long-term observation from ChinaFLUX sites, and the published data from other sites in China.

Since 2002, ChinaFLUX has conducted continuous carbon and water flux measurements at 9 sites using the open path eddy covariance (OPEC) system (Yu et al., 2006), which covered 4 forests, 3 grasslands, 1 cropland, and 1 wetland.

In addition to the ChinaFLUX observations, we also collected water flux data of other sites in China from published literature, dissertations and Free Fair-Use database of FLUXNET, which comprised a dataset covering 15 forests, 15 grasslands, 15 croplands, and 7 wetlands. We adopted the following methods to screen these data. First, water vapor (or latent heat) flux data were uniformly measured by EC method, and subsequently passed a series of processes performed by individual site researchers. Second, only sites with at least 1 year continuous flux measurements were selected. However, winter-time flux measurements data were unavailable at ten sites in cold climate zones, including Aro, Changling and Siziwang. Considering that these ecosystems usually represent one of the unique eco-regions and play an important role in spatial variation analysis, these sites were also accepted in our 
study. Due to the small contribution of ET during winter time to AET in these ecosystems, the data measured during growing season (or longer than growing season) were used to represent $\mathrm{AET}$.

After integrating the two data sources above, we constructed the most complete AET dataset in China up to now, which covered a total of 61 sites, containing 19 forest sites, 18 grassland sites, 16 cropland sites and 8 wetland sites. These sites have a broad spatial distribution and covered major climate zones and typical ecosystem types in China (Figure 1). Brief site descriptions for all 61 sites are provided in Table 1. Detailed information for each site could refer to the reference listed in Table 1.

For the sites with only 1 year data, the observed AET data were directly used in the analysis. For other sites with longer than 2 years of data records, the averaged values for AET during measuring periods were used to eliminate temporal variability in the analysis. The averaged climatic and vegetation factors mentioned below during corresponding observational periods were also used in the analysis.

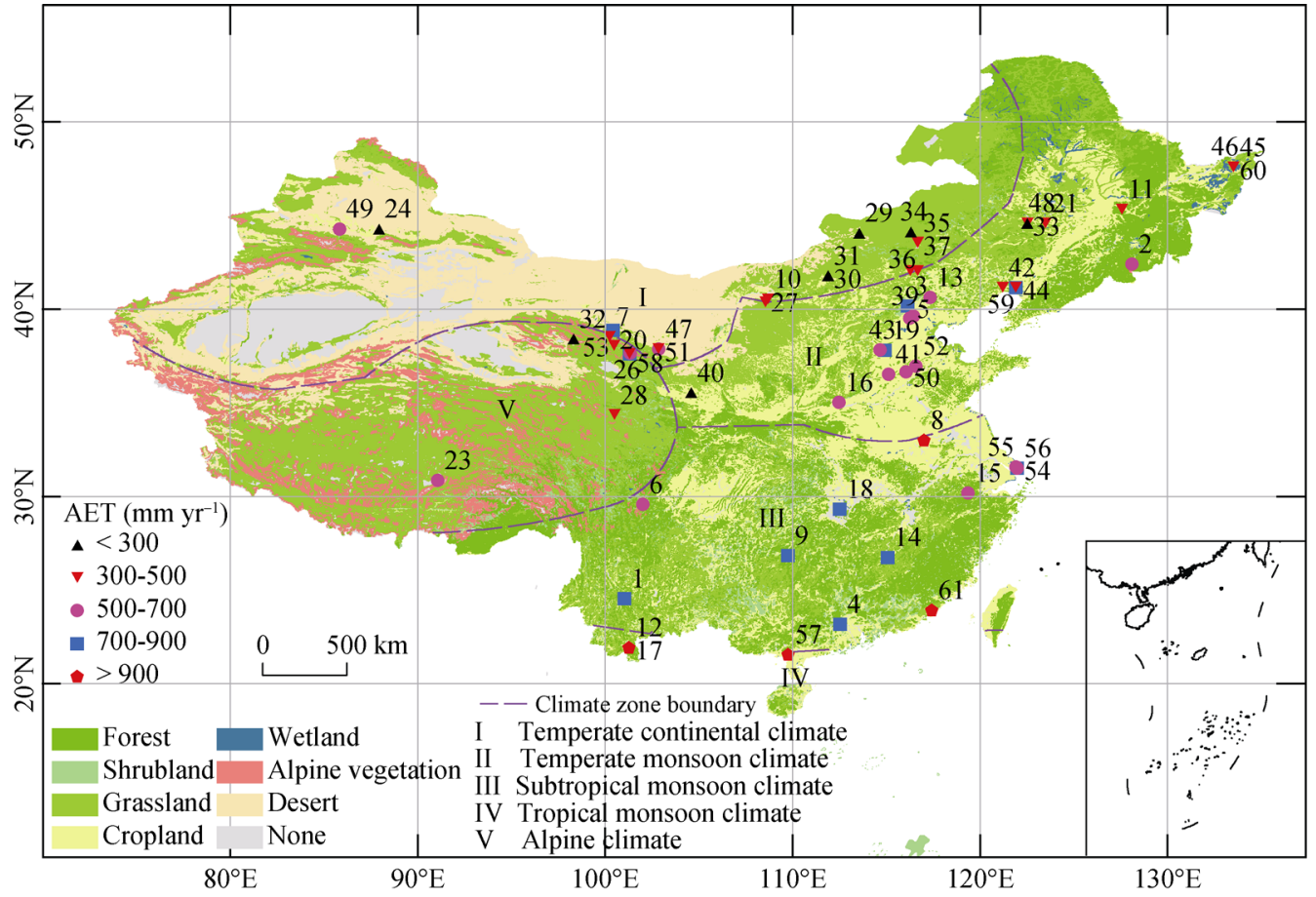

Figure 1 Location and spatial distribution of eddy covariance flux sites in China used in this study

Note: Base map is the vegetation map of China $(1: 1,000,000)$ (ECVMC, 2007). Symbols represent the location of flux sites. Site descriptions refer to Table 1.

\subsection{Data observation and process of ChinaFLUX}

OPEC system was used to measure carbon and water fluxes at ChinaFLUX sites. All signals were sampled with a frequency of $10 \mathrm{~Hz}$ and then calculated and recorded with a data logger at 30-min intervals. At each site, the meteorological variables including solar radiation, air temperature and relative humidity were measured at a frequency of $2 \mathrm{~s}$ and then recorded at 30-min intervals. Further details of the monitoring systems were presented by Chen et al. 


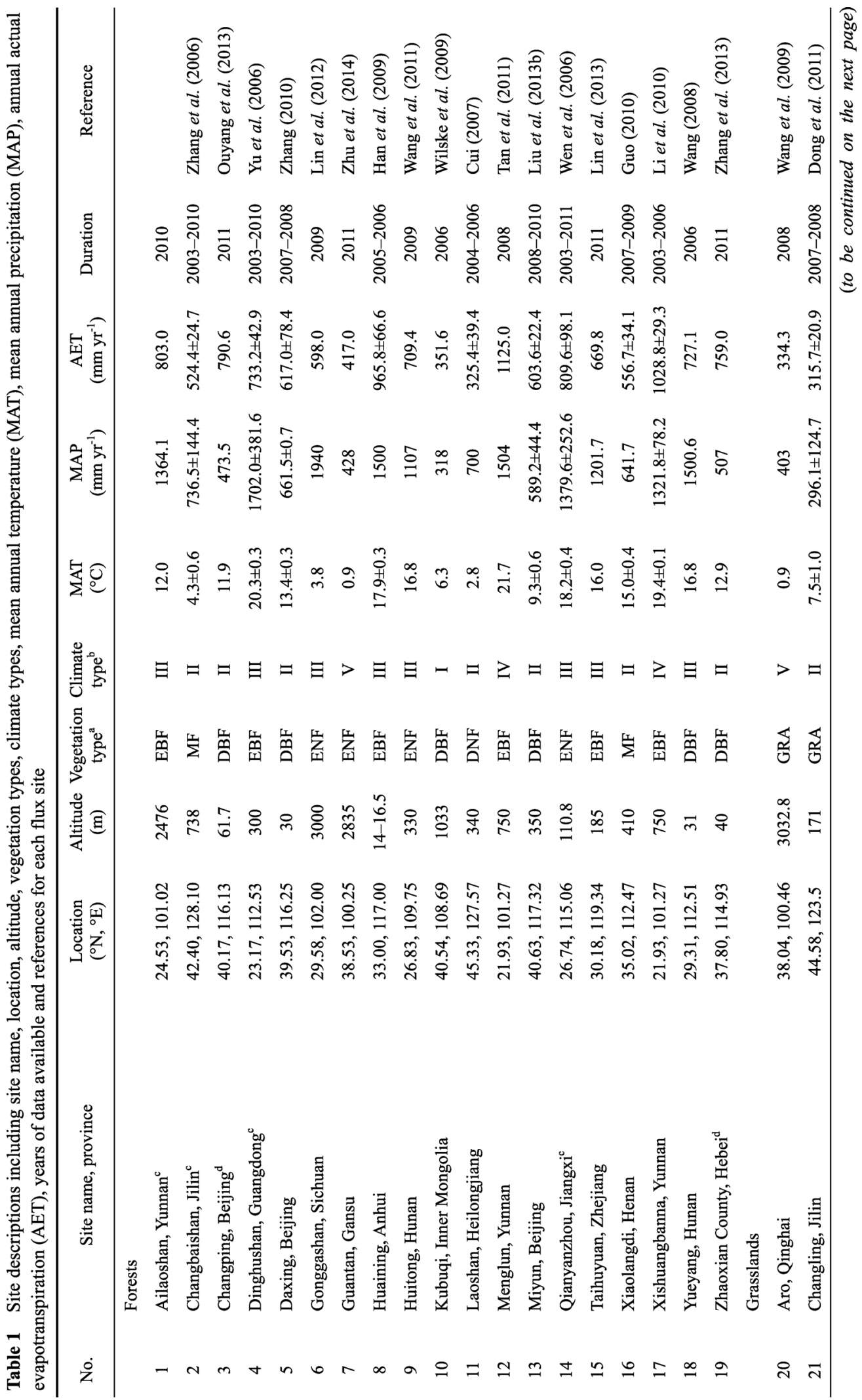




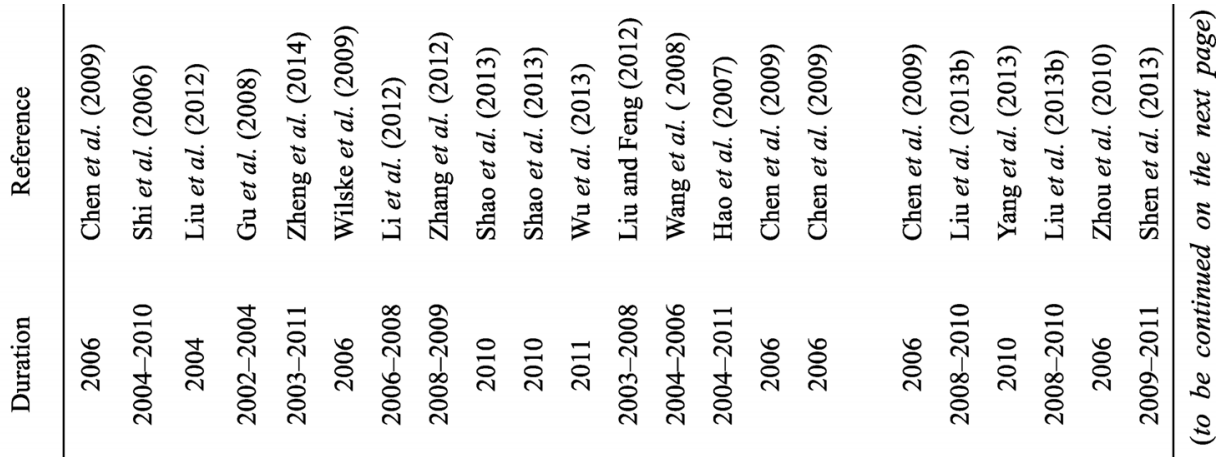

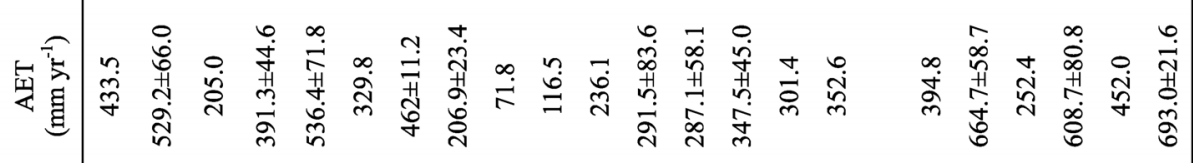

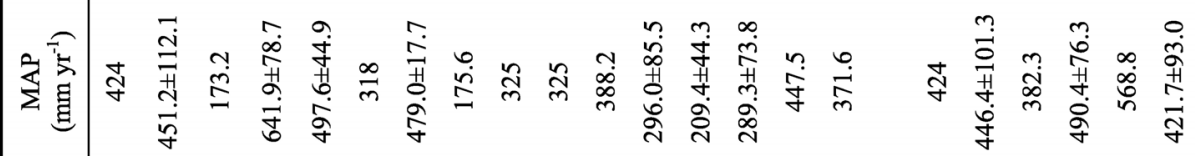

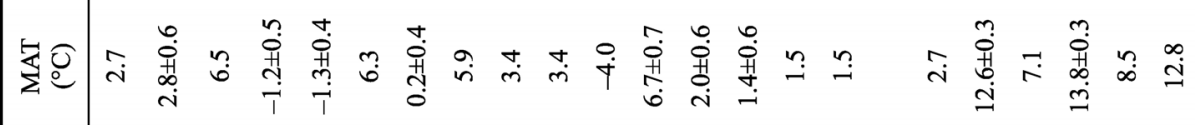

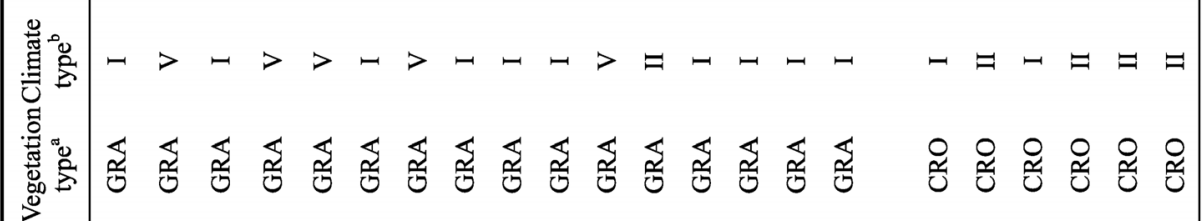

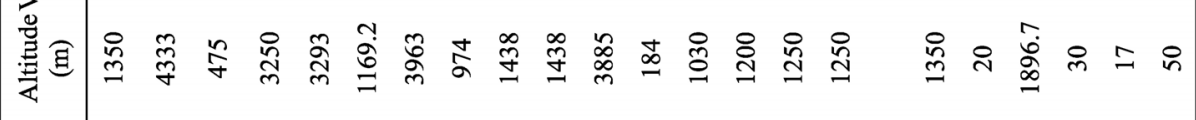

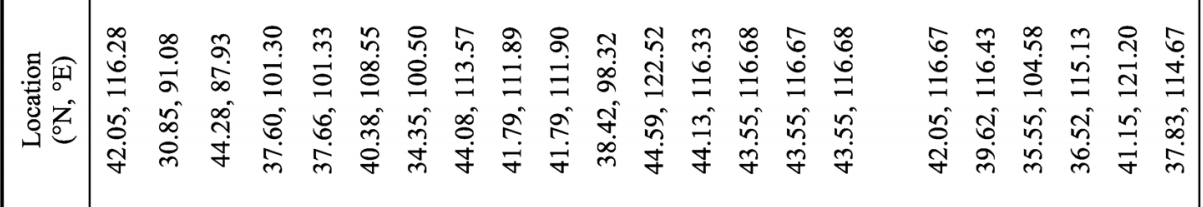

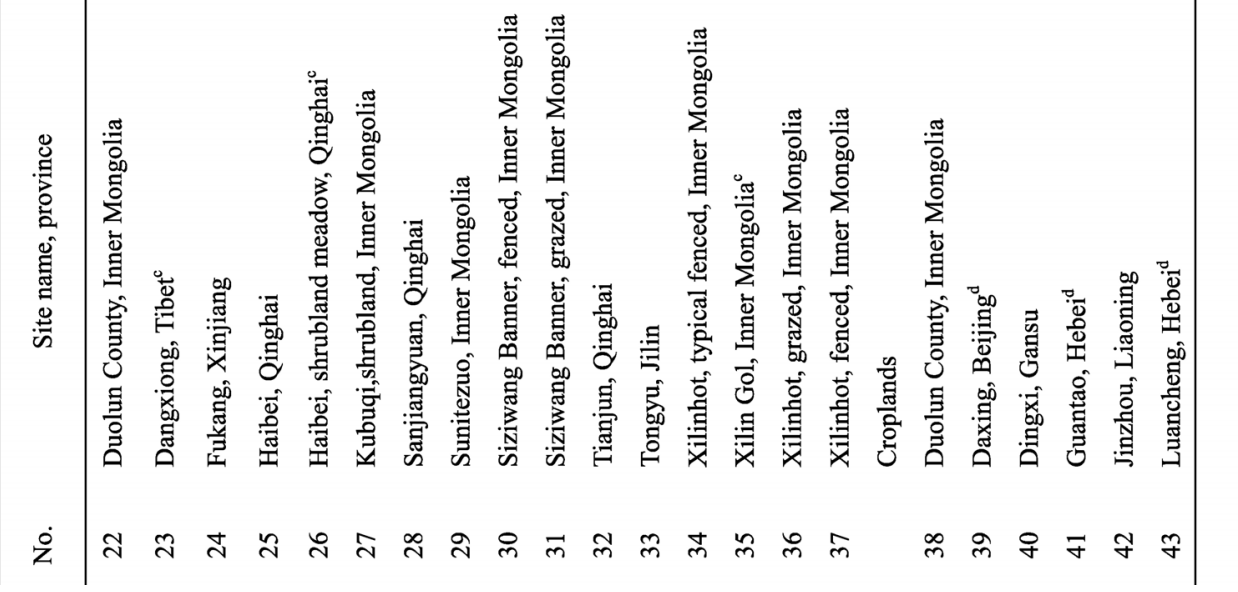




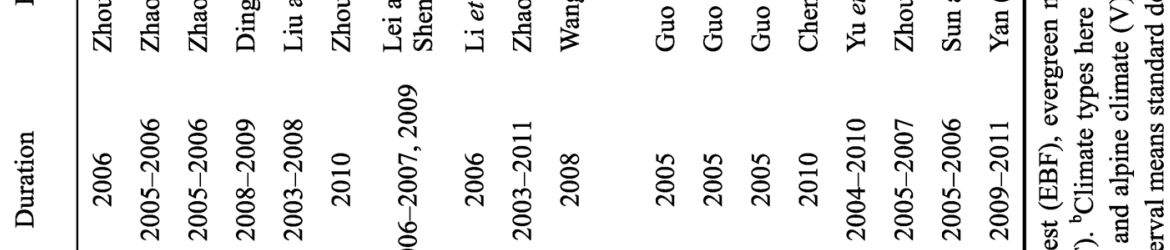

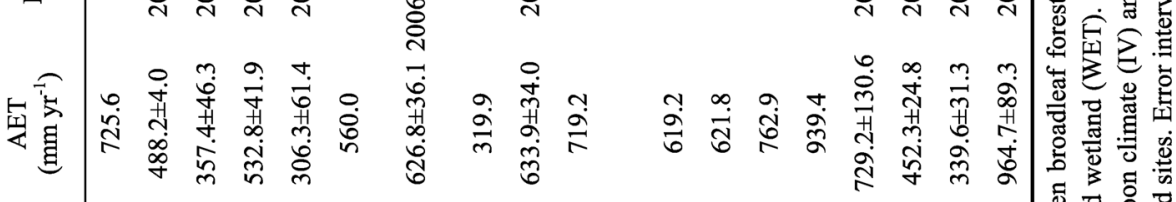

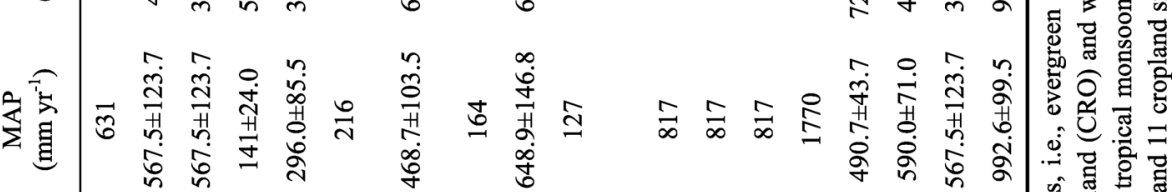

in in

车配

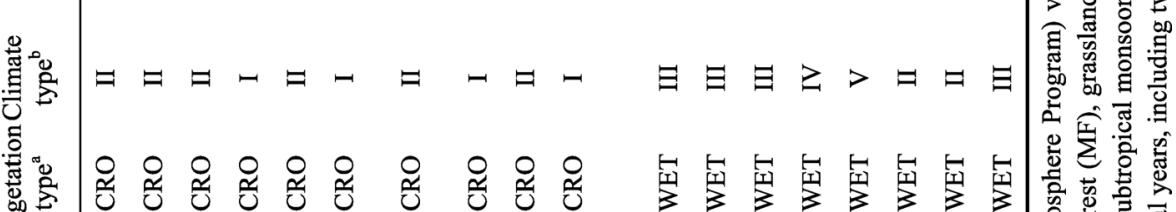

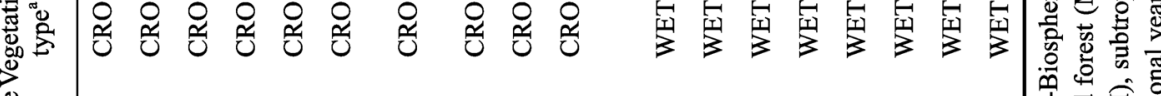

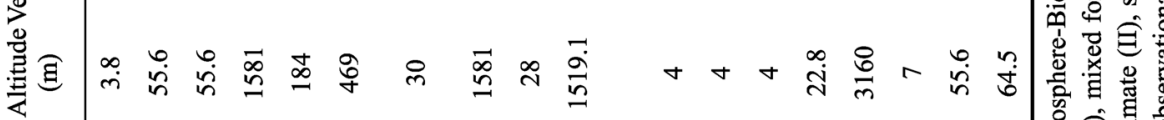

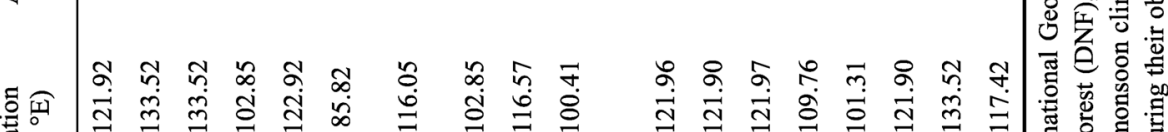

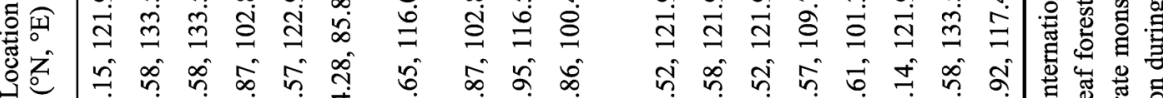

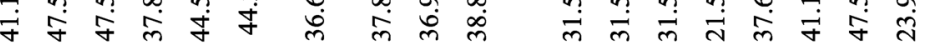

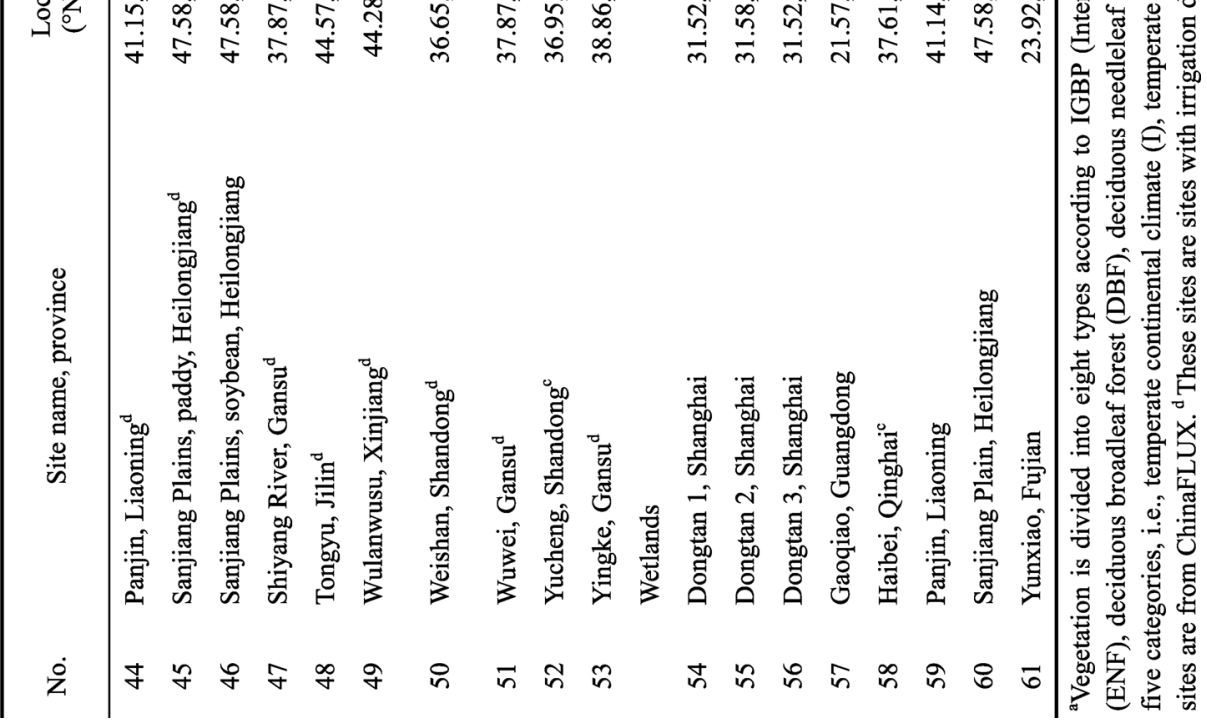


(2013) and Yu et al. (2014).

To process raw 30-min flux data, we applied the routine processing procedures recommended by ChinaFLUX, including three-dimensional coordinate rotation, Webb-PearmanLeuning (WPL) correction, storage flux calculation, outlier filter, and gap filling (Yu et al., 2006). The three-dimensional rotation was applied to make the average vertical wind speed to zero and to force the horizontal wind to the mean wind direction. WPL correction was used to adjust the effects of density change on $\mathrm{CO}_{2}$ and $\mathrm{H}_{2} \mathrm{O}$ fluxes (Webb et al., 1980). To screen low turbulence fluxes at night, site-specific friction velocity $\left(u^{*}\right)$ threshold was calculated according to Reichstein et al. (2005). Short data gaps $(<2 \mathrm{~h})$ in the water flux data were filled with linear interpolation, and longer gaps were filled with a look-up table method (Falge et al., 2001; Reichstein et al., 2005). All the data processing procedures specified above were performed with a Matlab program written in-house. See Yu et al. (2006) for more information about data quality control and gap filling.

\subsection{Climate data}

Six climatic factors, namely, total annual net radiation $\left(R_{\mathrm{n}}\right)$, total annual incident solar radiation $\left(R_{\mathrm{g}}\right)$, mean annual air temperature (MAT), mean annual precipitation (MAP), mean annual relative humidity $(\mathrm{RH})$ and mean annual vapor pressure deficit (VPD), were used to analyze the climate regulation of spatial variation in AET.

The measured MAT, MAP and $R_{\mathrm{n}}$ were used in this study. For the sites collected from literature, MAT, MAP and $R_{\mathrm{n}}$ data were also collected for their corresponding observational years. For some site-years with missing MAT or MAP, we filled the gaps with their multi-year averaged data. As to the $R_{\mathrm{g}}, \mathrm{RH}$ and VPD data, they were extracted from the corresponding interpolated dataset for each site-year. The gridded $R_{\mathrm{g}}$ data were obtained from the data center of the Chinese Ecosystem Research Network (He et al., 2004). The gridded data of RH and VPD were generated by the observed meteorological data at about 756 national basic meteorological stations in China, which were downloaded from the China meteorological data sharing service system (http://cdc.nmic.cn/home.do). We obtained the gridded RH and VPD data of China using the method of thin-plate smoothing splines in AUSPLIN software (Hutchinson, 1995). Then, the averaged climatic factors during observational periods for each site were used in the analysis.

\subsection{Vegetation data}

To evaluate how vegetation controls the spatial patterns of AET in China, we chose mean annual leaf area index (LAI) to represent the vegetation attributes characterizing vegetation status and canopy structure.

To control the variation in LAI measurements, we employed a MODIS LAI product (MOD15A2) with a temporal resolution of 8 days and a spatial resolution of $1 \mathrm{~km}$, which could highly match the spatial footprint of a flux tower (around $1 \mathrm{~km}^{2}$ ) (Göckede et al., 2004). For each site-year, we downloaded its MOD15A2 subset from the Oak Ridge National Laboratory Distributed Active Archive Center (ORNL DAAC, 2014). Then, all the 46 LAI values during one year were averaged as the annual LAI values for each site-year. Similarly, the mean annual LAI during measuring periods for each site were used in this analysis. 


\subsection{The published global ET products}

Based on the synthesized AET dataset (with 61 sites) above, we evaluated the performance and uncertainties of five published global ET products in predicting site-specific AET values in China. The five global ET products included a MODIS ET product (MOD16) (Mu et al., 2011), a merged ET synthesis product (MUE13) (Mueller et al., 2013), a normalized differential vegetation index (NDVI)-based ET product (ZHA10) (Zhang et al., 2010), a product based on a machine-learning algorithm (i.e., model tree ensemble) (JUN11) (Jung et al., 2011), and a product based on water balance approach (ZEN14) (Zeng et al., 2014). Their brief information was summarized in Table 2. More extensive descriptions could be found in specific references.

Table 2 Brief information on five published global evapotranspiration products

\begin{tabular}{|c|c|c|c|c|}
\hline Product & Algorithm & $\begin{array}{l}\text { Temporal and } \\
\text { spatial resolution }\end{array}$ & Time span & Reference \\
\hline MOD16 & Penman-Monteith equation & 8-day, $1 \mathrm{~km}$ & $2000-2013$ & Mu et al. (2011) \\
\hline MUE13 & Multi-dataset synthesis & Monthly, $1^{\circ}$ & 1989-2005 & Mueller et al. (2013) \\
\hline ZHA10 & $\begin{array}{l}\text { NDVI-based Penman-Monteith } \\
\text { equation }\end{array}$ & Monthly, $8 \mathrm{~km}$ & $1983-2006$ & Zhang et al. (2010) \\
\hline JUN11 & Empirical (machine-learning) & Monthly, $0.5^{\circ}$ & $1982-2011$ & Jung et al. (2011) \\
\hline ZEN14 & Water balance approach & Monthly, $0.5^{\circ}$ & 1982-2009 & Zeng et al. (2014) \\
\hline
\end{tabular}

Table 2 shows that the five ET products were different in both resolution and time span. Thus, when comparing with measured AET for a given site, we used the multi-year averaged yearly ET values during the time span for all the five ET products.

\subsection{Data statistical analysis}

Under the environment of SPSS 16.0 software, we applied analysis of variance and Tukey's multiple comparison tests to analyze the significance of differences in AET and AET/MAP among different climate and vegetation types. Curve Estimation tool was used to evaluate spatial relationships of AET with latitude, longitude, climatic factors and LAI, respectively. The difference or correlation was considered to be significant if $P<0.05$.

Meanwhile, path analysis was adopted to evaluate the dependence of AET on climatic factors and LAI using Amos 17.0 software. In the path diagram, we mainly evaluated the direct and indirect effects of $R_{\mathrm{n}}$, MAT, MAP, RH, VPD and LAI on the spatial variation in AET, respectively, and the direct effects of $R_{\mathrm{n}}$ on MAT. The direct effects were taken to be the standardized partial-regression coefficients, while the indirect effects were taken to be the sum of standardized partial regression coefficients of all possible paths.

When evaluating the five global ET products, four statistics were used including relative error (RE), coefficient of determination $\left(R^{2}\right)$, root mean square error (RMSE, $\mathrm{mm} \mathrm{yr}^{-1}$ ) and mean absolute bias (MAB, $\mathrm{mm} \mathrm{yr}^{-1}$ ).

$$
\begin{gathered}
\mathrm{RE}=\frac{y_{i}-x_{i}}{x_{i}} \\
R^{2}=\left(\frac{\sum_{i=1}^{n}\left(x_{i}-\bar{x}\right)\left(y_{i}-\bar{y}\right)}{\sqrt{\sum_{i=1}^{n}\left(x_{i}-\bar{x}\right)^{2} \cdot \sum_{i=1}^{n}\left(y_{i}-\bar{y}\right)^{2}}}\right)^{2}
\end{gathered}
$$




$$
\begin{aligned}
\operatorname{RMSE} & =\sqrt{\frac{\sum_{i=1}^{n}\left(y_{i}-x_{i}\right)^{2}}{n}} \\
\mathrm{MAB} & =\frac{\sum_{i=1}^{n}\left|y_{i}-x_{i}\right|}{n}
\end{aligned}
$$

where $x_{i}$ and $y_{i}$ are measured AET value from flux towers and predicted AET value extracted from each corresponding global ET dataset for the $i$ th site, respectively. $\bar{x}$ and $\bar{y}$ are the averages of the measured and predicted data, respectively. $n$ is the total number of sites (i.e., 61). $R^{2}$ represents the fraction of the variation in the observed data that can be explained by the global ET dataset. RE, RMSE and MAB are used to quantify the biases between the predicted data and the measurements.

The spatial distribution figure of flux sites in China was plotted by ArcGIS 10.0 software, and all the other figures were plotted by Matlab R2009a software.

\section{Results}

\subsection{Statistic characteristics of AET and AET/MAP in China}

Analysis of variance showed that AET differed significantly among both different vegetation types and climate types in China $(P<0.05)$. Then multiple comparisons across major vegetation types and climate zones were explored (Figure $2 \mathrm{a}$ ). Regarding vegetation types, broadleaf forests had the highest AET with mean AET of $732.5 \pm 207.3 \mathrm{~mm} \mathrm{yr}^{-1}$, and wetlands came second with mean AET of $678.6 \pm 217.9 \mathrm{~mm} \mathrm{yr}^{-1}$. For the cropland ecosystems, AET of irrigated croplands were much higher than AET of rainfed croplands (Table 1), with mean AET of $521.0 \pm 157.5 \mathrm{~mm} \mathrm{yr}^{-1}$. AET of grasslands tended to be the lowest with an average of $318.9 \pm 125.0 \mathrm{~mm} \mathrm{yr}^{-1}$ (Figure 2a). Turning to climate types, AET showed an obvious increasing trend successively from temperate continental, alpine, temperate monsoon, subtropical monsoon, to tropical monsoon climate (Figure 2b). Overall, AET values of terrestrial ecosystems in China ranged from 71.8 to $1125.0 \mathrm{~mm} \mathrm{yr}^{-1}$, with an overall mean and median AET of $534.7 \pm 232.8 \mathrm{~mm} \mathrm{yr}^{-1}$ and $529.2 \mathrm{~mm} \mathrm{yr}^{-1}$, respectively. The minimum and maximum AET was found in Inner Mongolia desert steppe (No.30 in Table 1) and tropical forest (No.12 in Table 1), respectively.

The ratio of AET to MAP (AET/MAP) was defined to describe the water budget status in natural terrestrial ecosystems of China in this study. Results showed that there were no significant differences in AET/MAP values across vegetation types in China $(P>0.05$, Figure $2 \mathrm{a})$, though grasslands generally had larger AET/MAP values than forests (broadleaf and needleleaf forests). Regarding climate types, AET/MAP differed significantly among different climate types in China $(P=0.0315)$, but only the subtropical monsoon climate and alpine climate types had significant differences from each other $(P=0.047)$ (Figure $2 \mathrm{~b})$. We also noted that AET/MAP of temperate continental and alpine climate zones tended to be larger than that of three monsoon climate zones (Figure 2b). As a whole, without taking irrigated ecosystems into account, the overall mean and median AET/MAP of terrestrial ecosystems in all sites was $0.82 \pm 0.28$ and 0.79 , respectively. 

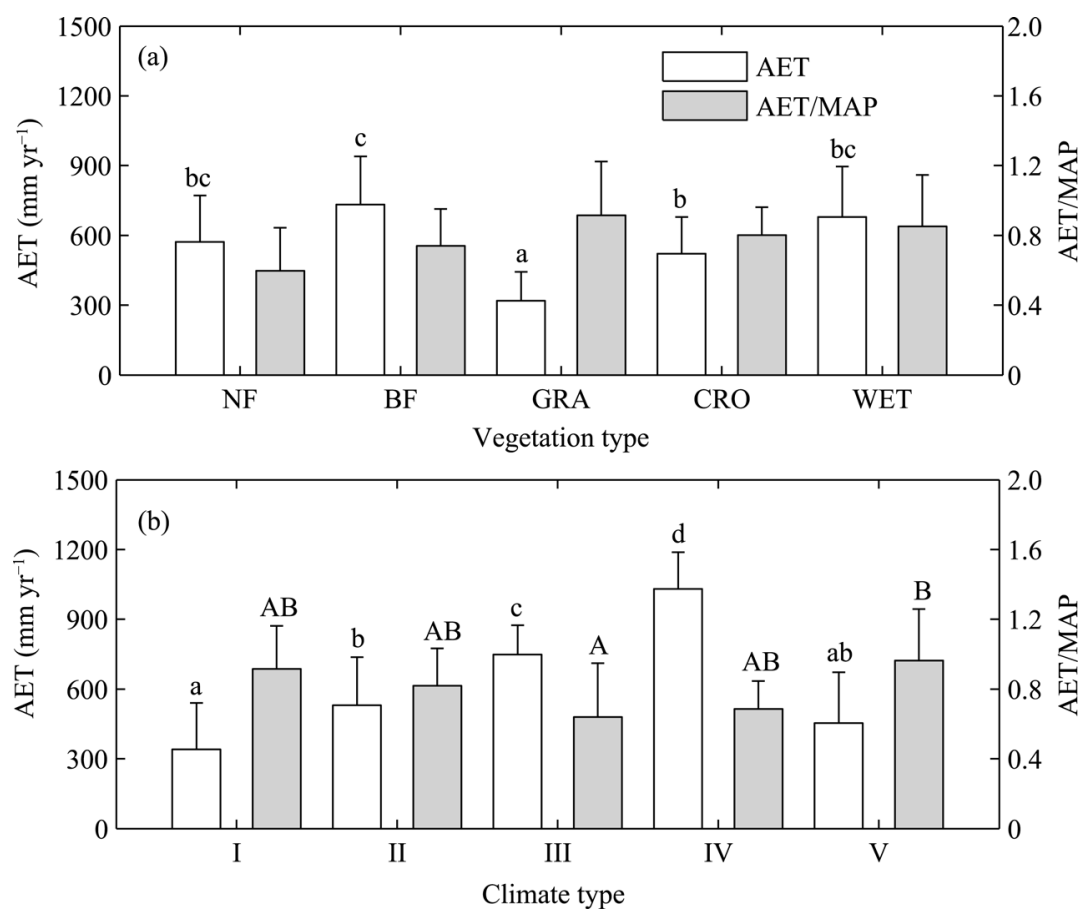

Figure 2 Statistic characteristics of AET and AET/MAP for different vegetation (a) and climate (b) types in China

Note: Climate and vegetation types refer to Table 1, in which EBF, DBF and MF were summarized as broadleaf forest (BF), while ENF and DNF were merged as needleleaf forest (NF). Thus, five climate and vegetation types were considered, respectively. For AET/MAP analyses, only non-irrigated sites were considered. Different lowercase and capital letters above bars indicate significant differences in AET and AET/MAP at the level of $\alpha=0.05$ based on Tukey's multiple comparison tests, respectively. $\mathrm{BF}=$ broadleaf forest, $\mathrm{NF}=$ needleleaf forest, $\mathrm{GRA}=$ grassland, $\mathrm{CRO}=$ cropland, $\mathrm{WET}=$ wetland, $\mathrm{I}=$ temperate continental climate, $\mathrm{II}=$ temperate monsoon climate, $\mathrm{III}=$ subtropical monsoon climate, $\mathrm{IV}=$ tropical monsoon climate, and $\mathrm{V}=$ alpine climate.

\subsection{Latitudinal and longitudinal patterns of AET}

AET of terrestrial ecosystems in China showed an obvious latitudinal pattern and this pattern did not change when different ecosystem types were included (Figure 3a). AET declined linearly with the increase of latitude $(P<0.0001)$. With $1^{\circ}$ increase of latitude, AET decreased by $24.94 \mathrm{~mm} \mathrm{yr}^{-1}$. In contrast, the longitudinal pattern of AET in China was much more complex (Figure 3b). In general, AET decreased with the increase of longitude but not significantly $(P=0.6876)$.

\subsection{Spatial relationships of AET with climatic factors and vegetation attributes}

We first tested the significant effects of vegetation and climate types on the spatial variation in AET using an analysis of variance (Table 3, two-way, unbalanced, with interaction). Both the climate and vegetation effects were significant $(P<0.0001)$ but their interaction effects were not significant $(P=0.4120)$ (Table 3$)$. Then, the effects of main climatic factors and vegetation attributes were explored next.

Figure 4 shows the spatial relationships of AET with main climate factors. The spatial 

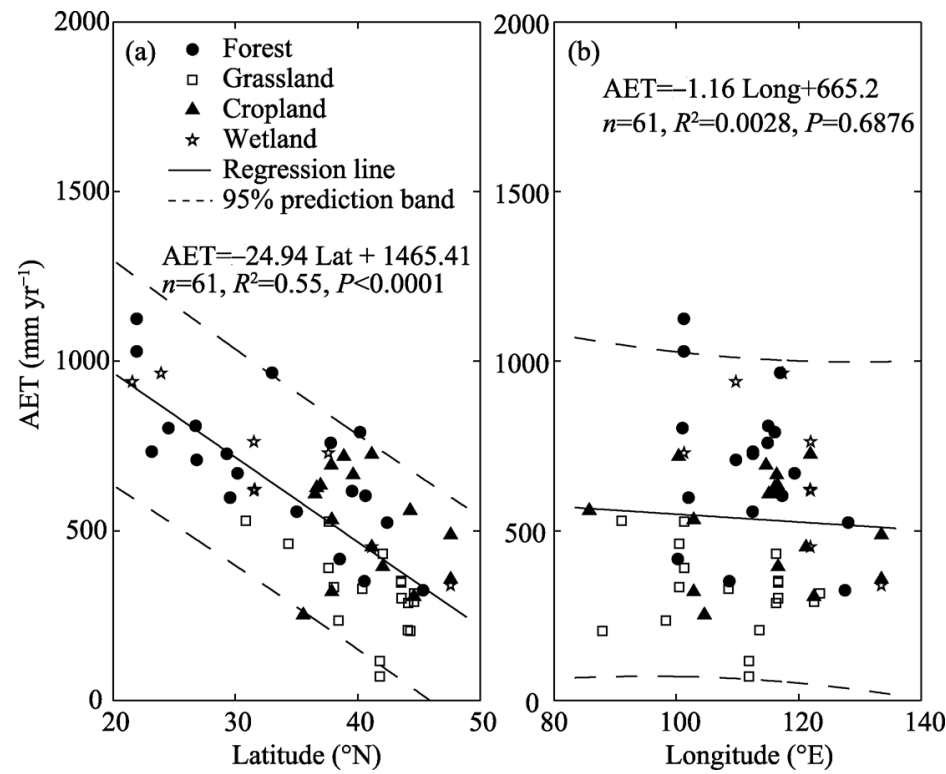

Figure 3 Latitudinal (a) and longitudinal (b) patterns of AET in terrestrial ecosystems of China
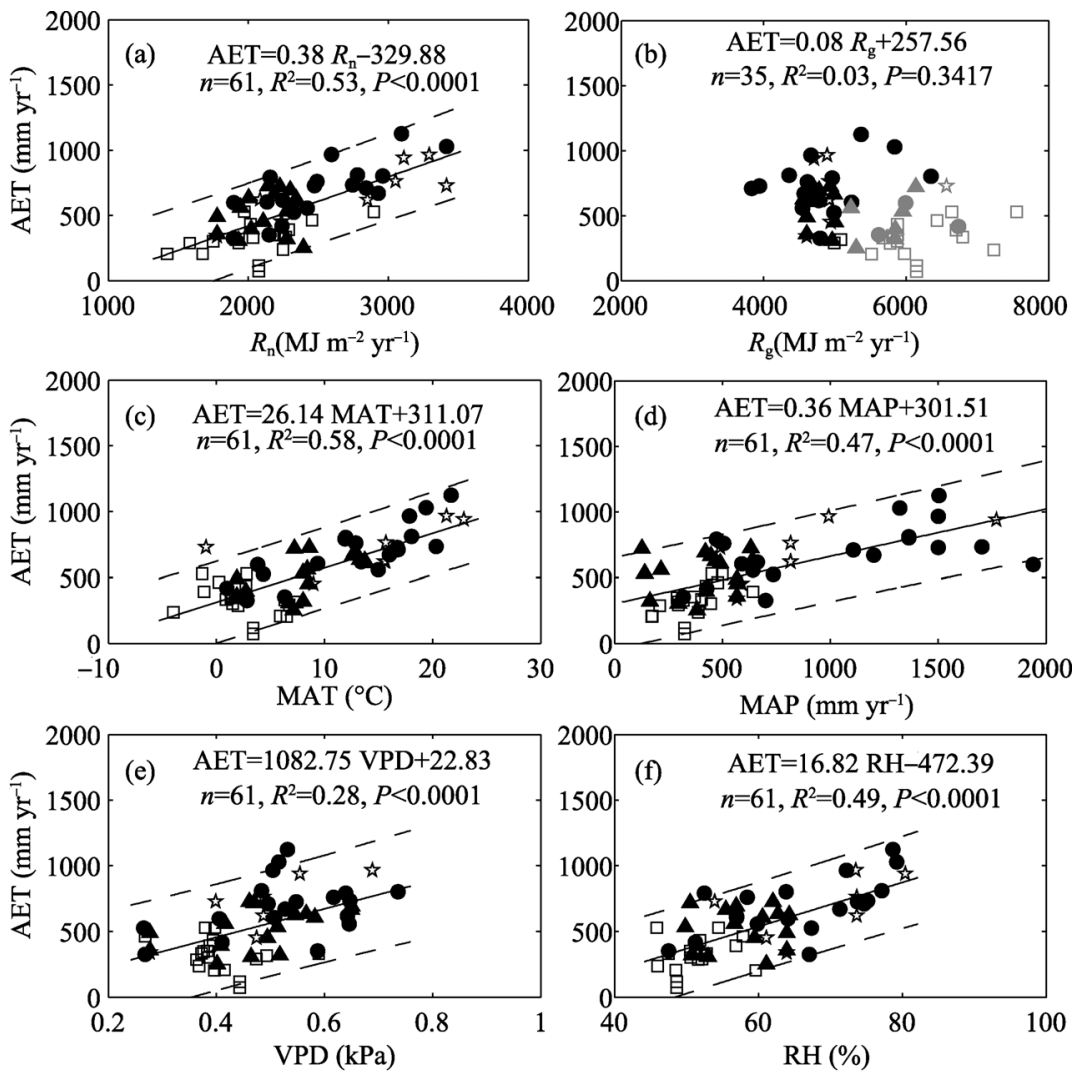

- Forest $\square$ Grassland $\triangle$ Cropland \& Wetland — Regression line - - -95\% prediction band

Figure 4 Spatial relationships of AET with climatic factors in China

(a) $R_{\mathrm{n}}=$ total annual net radiation; (b) $R_{\mathrm{g}}=$ total annual incident solar radiation. Grey markers in panel (b) are sites in the Qinghai-Tibetan Plateau, Inner Mongolia and northwest regions of China. Here the regression line was fitted using the data of other sites with black markers; (c) MAT=mean annual air temperature; (d) MAP=mean annual precipitation; (e) $\mathrm{VPD}=$ mean annual vapor pressure deficit; and (f) $\mathrm{RH}=$ mean annual relative humidity. 
Table 3 Results of a two-way, unbalanced analysis of variance testing effects of vegetation type, climate type and their interaction on the spatial variation in AET

\begin{tabular}{lccccc}
\hline \multicolumn{1}{c}{ Source } & SS & df & MS & F & $P$ value \\
\hline Corrected model & 2504711.39 & 15 & 166980.76 & 10.07 & $<0.0001$ \\
Intercept & 11070002.82 & 1 & 11070002.82 & 667.32 & $<0.0001$ \\
Vegetation type & 415734.48 & 4 & 103933.62 & 6.27 & 0.0004 \\
Climate type & 781908.08 & 4 & 195477.02 & 11.78 & $<0.0001$ \\
Interaction & 121712.67 & 7 & 17387.52 & 1.05 & 0.4120 \\
Error & 746498.67 & 45 & 16588.86 & & \\
Total & 20694573.86 & 61 & & & \\
Corrected total & 3251210.06 & 60 & & & \\
\hline
\end{tabular}

Note: Climate and vegetation types refer to Table 1, in which EBF, DBF and MF were summarized as broadleaf forest (BF), while ENF and DNF were merged as needle forest (NF). Thus, five climate and vegetation types were considered, respectively. $\mathrm{SS}=$ sum of squares, $\mathrm{df}=$ degrees of freedom, $\mathrm{MS}=$ mean squares, $\mathrm{F}=\mathrm{F}$ statistic.

patterns of total annual net radiation $\left(R_{\mathrm{n}}\right)$ and mean annual air temperature (MAT) closely correlated with that of AET, contributing $53 \%$ and $58 \%$ to the spatial variation in AET, respectively (Figures $4 \mathrm{a}$ and $4 \mathrm{c}$ ). But the spatial relationship of total annual incident solar radiation $\left(R_{\mathrm{g}}\right)$ with AET was much weaker and negative due to the impacts of the Qinghai-Tibet Plateau $\left(R^{2}=\right.$ $0.13, P=0.0045$ ) (Figure $4 \mathrm{~b}$ ). When excluding the sites strongly affected by the Qinghai-Tibet Plateau (identified with grey markers in Figure 4b), the spatial relationship of AET with $R_{\mathrm{g}}$ became non-significant $(P=0.3417)$ (Figure $4 b)$. Regression analysis also indicated that, the spatial patterns of MAP and mean annual relative humidity $(\mathrm{RH})$ were pronouncedly correlated with that of AET, contributing $47 \%$ and $49 \%$ to the spatial variation in AET, respectively $(P<0.0001)$ (Figures $4 \mathrm{~d}$ and $4 \mathrm{f})$. Besides, the spatial patterns of mean annual vapor pressure deficit (VPD) could also explain about $28 \%$ of the spatial variation in AET (Figure 4e).

Except vegetation type, mean annual leaf area index (LAI) is another important biotic parameter characterizing vegetation attributes, which could account for $46 \%$ of the spatial variation in AET $(P<0.0001)$ (Figure 5a). A clear logarithmic relationship between LAI and $\operatorname{AET}\left(R^{2}=0.46\right.$,
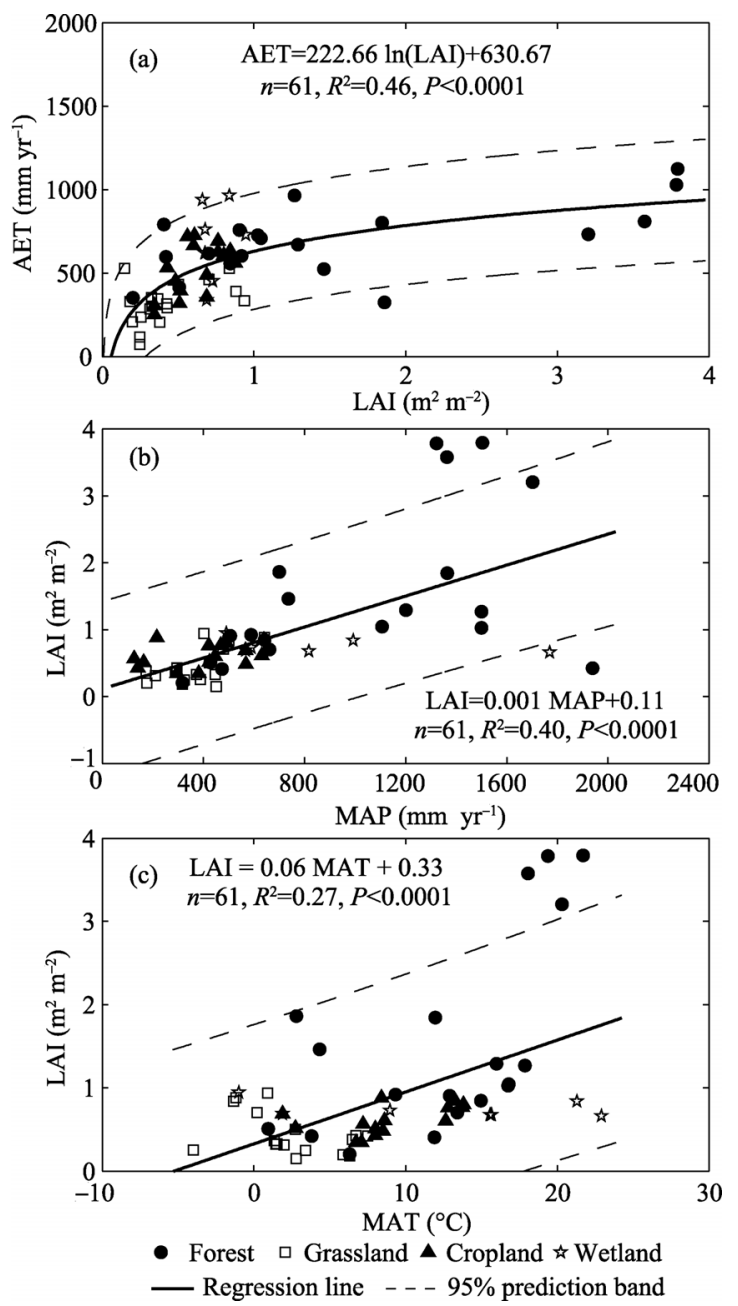

Figure 5 Spatial relationship of LAI with AET (a) and effects of MAP (b) and MAT (c) on the spatial variation in LAI 
$P<0.0001)$ was found to be stronger than a linear $\left(R^{2}=0.36, P<0.0001\right)$ and quadratic $\left(R^{2}=0.42, P<0.0001\right)$ relationship. Meanwhile, the spatial patterns of LAI were strongly affected by that of climatic factors, in which MAP and MAT could explain about $40 \%$ and $27 \%$ of the across-site variation in LAI, respectively (Figures $5 \mathrm{~b}$ and $5 \mathrm{c}$ ).

For irrigated ecosystems, the added water from irrigation might affect the spatial response patterns of AET to climatic factors and vegetation attributes. When removing irrigated ecosystems, the coefficients of determination $\left(R^{2}\right)$ for the spatial relationship of AET with MAP and RH increased from 0.47 and 0.49 to 0.65 and 0.62 , respectively, while the spatial relationship of AET with

Table 4 Coefficients of determination for spatial relationships of AET with climatic factors and LAI

\begin{tabular}{ccc}
\hline & All sites & Non-irrigated sites $^{\mathrm{a}}$ \\
\hline$R_{\mathrm{n}}$ & 0.53 & 0.62 \\
MAT & 0.58 & 0.60 \\
MAP & 0.47 & 0.65 \\
VPD & 0.28 & 0.27 \\
RH & 0.49 & 0.62 \\
LAI & 0.46 & 0.52 \\
\hline
\end{tabular}

${ }^{a} 13$ irrigated sites containing 2 forest sites and 11 cropland sites (Table 1) were removed. other factors nearly did not change (Table 4).

Path analysis was further adopted to evaluate the dependence of AET on these factors. Because the correlation between $R_{\mathrm{g}}$ and AET was weak, $R_{\mathrm{g}}$ was not considered in path analysis. Path diagram shows that $R_{\mathrm{n}}$, MAP and MAT are the dominant direct factors affecting the spatial patterns of AET in China (Figure 6), while the direct effects of LAI, VPD and RH on AET are not significant (thus not shown in Figure 6). Besides, $R_{\mathrm{n}}$ could also indirectly affect the spatial variation in AET through influences on MAT, which made the total effects of $R_{\mathrm{n}}$ even stronger (Figure 6).

Based on path analysis results, an empirical equation involving $R_{\mathrm{n}}$, MAP and MAT was developed (Equation 5) using multiple linear regression analysis. This equation could explain around $84 \%$ of spatial variation in AET of terrestrial ecosystems in China.

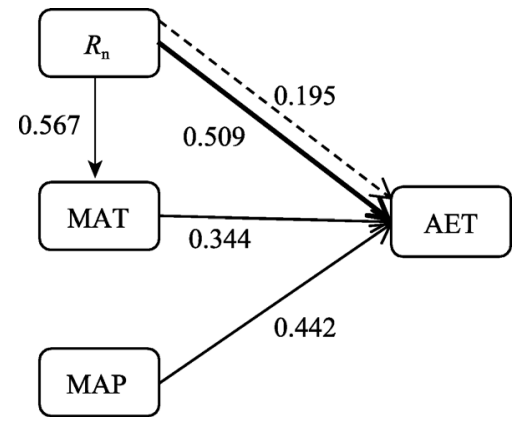

Figure 6 Path diagram that illustrates the dependence of AET on climatic variables

Data represent standardized partial-regression coefficients. Solid lines indicate direct effects and dashed line denotes indirect effects. The width of lines describes path strength of effects, and thicker lines denote larger path coefficients. In the path analysis, the direct effects of LAI, RH and VPD on AET were not significant $(P>0.05)$. Thus, their corresponding paths were not shown in this diagram.

$$
\mathrm{AET}=0.19 \mathrm{MAP}+0.21 R_{n}+9.49 \mathrm{MAT}-191.123\left(n=48, R^{2}=0.84, \mathrm{RMSE}=101.23, P<0.0001\right)(5)
$$

\subsection{Evaluation of five global ET products over China}

We evaluated five published global ET products using eddy-covariance AET values of 61 sites as the standards. Results indicated that all the five global ET products had good performance in describing across-site variation in AET, with $R^{2}$ ranging from 0.58 to 0.68 (Figure 7). Nevertheless, they had different degrees of deviations in simulating site-specific AET values, with relative error (RE) mostly falling between $-50 \%$ and $50 \%$. But RE reached $200 \%$ or greater for the sites with low vegetation coverage (No.30 in Table 1) (Figure 7). Overall, the 
five products had root mean square error (RMSE) ranging from 103.50 to $226.50 \mathrm{~mm} \mathrm{yr}^{-1}$, and mean absolute bias (MAB) ranging from 105.12 to $153.98 \mathrm{~mm} \mathrm{yr}^{-1}$ (Figure 7). All the five products simulated lower averaged AET values for the total 61 sites than eddy-covariance method $\left(534.7 \pm 232.8 \mathrm{~mm} \mathrm{yr}^{-1}\right)$, with the largest deviation from ZHA10 $\left(421.4 \pm 168.9 \mathrm{~mm} \mathrm{yr}^{-1}\right)$ and smaller deviations from JUN11 $\left(514.4 \pm 219.0 \mathrm{~mm} \mathrm{yr}^{-1}\right)$ and ZEN14 (521.5 $\left.\pm 348.5 \mathrm{~mm} \mathrm{yr}^{-1}\right)$.
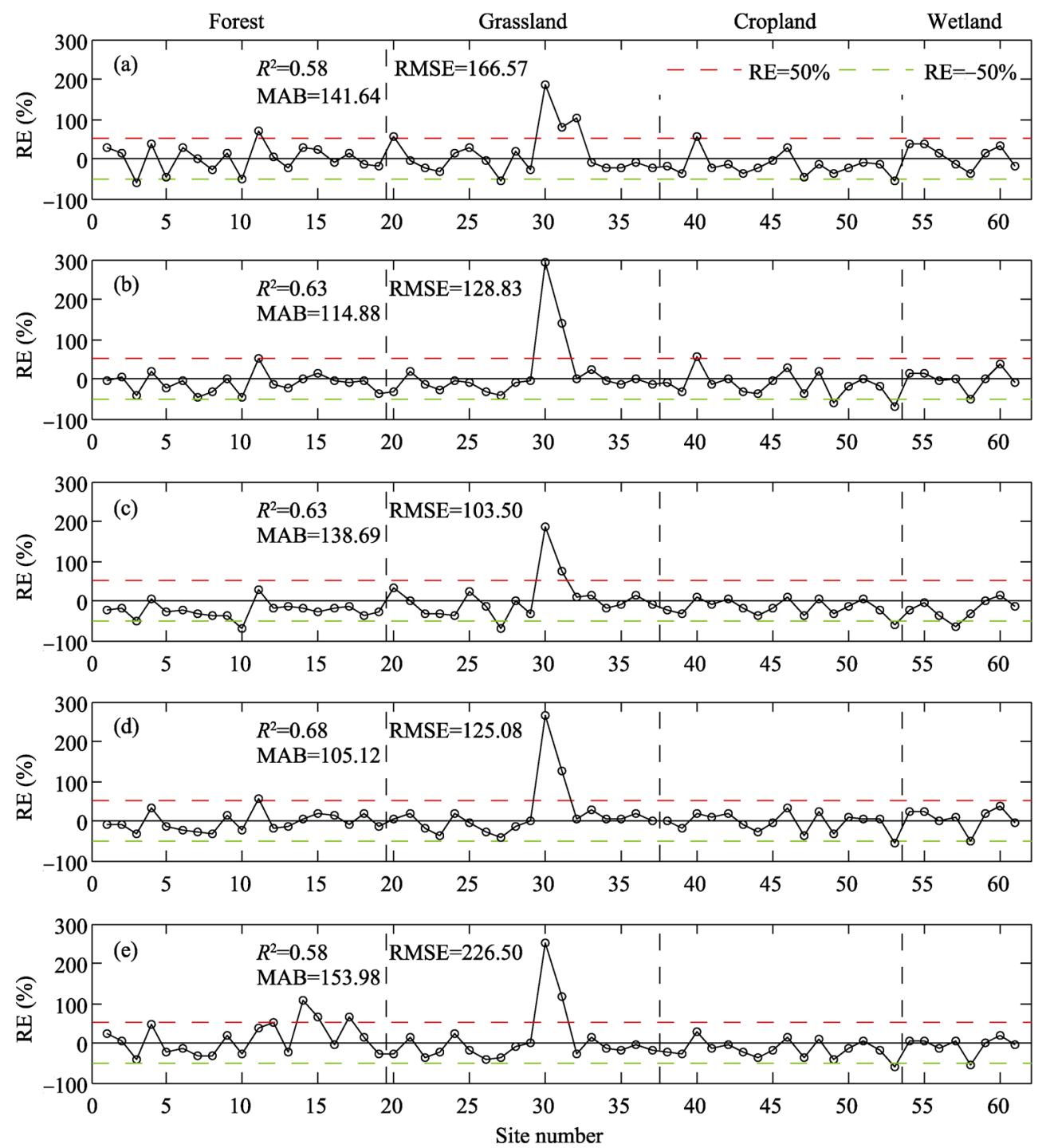

Figure 7 Relative error (RE) for global ET products of MOD16 (a), MUE13 (b), ZHA10 (c), JUN11 (d), and ZEN14 (e) in simulating site-specific AET in China. Site numbers refer to Table 1.

\section{Discussion}

\subsection{AET and AET/MAP in China}

By synthesizing water flux data obtained by eddy covariance method in China, we con- 
structed the most complete AET dataset in China up to now. Based on this dataset, we quantified the statistic characteristics of AET and AET/MAP, and then evaluated the uncertainties of five global ET products in simulating AET values of terrestrial ecosystems in China. Although the spatial patterns of AET described by the five global ET products highly agreed with our measurements, large obvious uncertainties in site-specific AET values existed, especially for sites with low vegetation coverage (Figure 7), and the averaged AET values for the total 61 sites simulated by all the five products were lower than that measured by eddy-covariance method $\left(534.7 \pm 232.8 \mathrm{~mm} \mathrm{yr}^{-1}\right)$. This is mainly because very few observation data in China have been used in the parameterization and/or validation of these global ET products. Therefore, to improve the accuracy of global ET products in evaluating AET over China, it is necessary to involve more observation data of China in their parameterization or validation, while our AET dataset would provide a data source for it.

Among the major findings reported here we found that the geographic variation in AET/MAP is mainly controlled by the climate patterns in China, while no significant differences were observed across vegetation types (Figure 2). Generally, forests are expected to evaporate and transpire a larger fraction of MAP than that of grasslands, because of their deeper and more extensive root systems, and higher leaf area and associated higher interception capacity (Williams et al., 2012). However, on the contrary, our results indicated that grasslands (0.92) generally had larger AET/MAP values than forests (between 0.60 and 0.74 ) (Figure 2a), which agreed with the global synthesis results of Williams et al. (2012). This is because that grasslands in China mainly locate in the temperate continental and alpine climate zones, and forests mainly locate in the monsoon climate zones, while AET/MAP of temperate continental and alpine climate zones tended to be larger than that of monsoon climate zones (Figure 2b). These two aspects hence make AET/MAP generally higher in grasslands compared to forests.

We also found that the mean AET/MAP of included sites (ranged from 0.60 to 0.92 , non-irrigated) was consistently larger than the global mean AET/MAP reported in Oki and Kanae (2006) (ranged from 0.54 to 0.68 ) for a given vegetation type, which was also attributed to the climatic regulation of AET/MAP. Affected by local climatic conditions, large differences exist in AET/MAP values among different climate zones for a specific vegetation type (Table 1). The AET/MAP values are generally higher for ecosystems in temperate and alpine climate zones of China, which thus makes the mean AET/MAP in China generally higher than the corresponding global mean AET/MAP value.

\subsection{Effects of climate and vegetation on the spatial variation in AET}

Our analyses confirmed the latitudinal pattern of AET and its significant relationships with MAP, MAT and vegetation types reported in previous studies (Jung et al., 2011; Brümmer et al., 2012; Xiao et al., 2013). Given the pronounced covariation or interactive effects among climatic factors (e.g., MAT vs. $R_{\mathrm{n}}$, MAT vs, VPD, MAP vs. RH) and vegetation attributes (e.g., MAT vs. LAI, MAP vs. LAI) (Law et al., 2002), it is not surprised that the spatial patterns of AET significantly correlated with that of $R_{\mathrm{n}}, \mathrm{VPD}, \mathrm{RH}$ and LAI. To better understand the climate and vegetation controls on the spatial variation in AET, it is important to comprehensively understand the roles of different potential influencing factors, especially vegetation attributes, in regulating the spatial patterns of AET. 
Our findings suggested that the spatial variation of climatic conditions played a key role in shaping the spatial patterns of AET in China. It has been reported that the long-term mean AET (or water balance) was primarily controlled by the balance between water supply and atmospheric evaporation demand at catchment scales (Budyko, 1974; Yang et al., 2007). Our analyses also manifested that the climate controls on spatial variation in AET of terrestrial ecosystems in China were also mainly reflected by water supply and atmospheric evaporation demand. Water supply affected the spatial patterns of AET mainly via determining surface water availability and atmospheric dryness, while MAP and RH could reflect their magnitudes, respectively. Thus, the spatial patterns of AET were significantly positively correlated with that of MAP and RH (Figures $4 \mathrm{~d}$ and $4 \mathrm{f}$ ). When ecosystem water availability was altered by anthropogenic irrigation, the spatial relationships of AET with MAP and RH were thereby changed (Table 4). In the meantime, the atmospheric evaporation demand could be reflected by the magnitudes of $R_{\mathrm{n}}$ and MAT. Because VPD was calculated from MAT, thus the positively spatial relationships of AET with $R_{\mathrm{n}}$, MAT and VPD were observed (Figures $4 \mathrm{a}, 4 \mathrm{c}$ and $4 \mathrm{e}$ ). Our finding also revealed that the climate regulation on spatial variation in AET was achieved through balancing the relationship between water supply and atmospheric evaporation demand as well. For example, although the MAP at Gonggashan site (No.6 in Table 1) exceeds $1900 \mathrm{~mm} \mathrm{yr}^{-1}$, its MAT is very low $\left(3.8^{\circ} \mathrm{C}\right)$, which hence makes small AET value $\left(<600 \mathrm{~mm} \mathrm{yr}^{-1}\right)$.

Our study also revealed that the spatial patterns of AET pronouncedly correlated with the vegetation pattern in China. Results showed that AET differed significantly among different vegetation types (Figure 2a), and the spatial patterns of AET were highly correlated with that of LAI (Figure 5a). Previous studies have demonstrated that the spatial variation in LAI could affect the spatial patterns of different components of AET. For example, evaporation of canopy interception depended on LAI (Jung et al., 2011), and the proportion of AET that evaporated from soil surfaces increased as LAI decreased (Law et al., 2002). Thus, it is seemly that LAI regulates the spatial patterns of AET mainly by influencing the proportion of different AET components (i.e., vegetation transpiration, soil evaporation and evaporation of canopy interception).

The effects of vegetation pattern on the spatial variation in AET are likely because climate pattern determines vegetation pattern. Since different types of vegetation have different cold- and drought-resistance capability, the geographic variation in climatic conditions determines the geographic distribution of vegetation types. These various vegetation types represent varying vegetation characteristics (e.g., LAI), thus climate pattern determines the spatial patterns of vegetation attributes. For instance, MAP and MAT patterns in China affected the spatial variation in LAI (Figures $5 \mathrm{~b}$ and $5 \mathrm{c}$ ). Therefore, the evergreen broadleaf forests in tropical humid climate zones have higher LAI and AET, while grasslands in cold/arid climate zones generally have small LAI and thus small AET (Table 1). However, there was a strong logarithmic relationship between AET and LAI in China rather than a linear relationship (Figure 5a), which is determined by the geographic patterns of LAI and atmospheric evaporation demand in China. The forest sites with LAI larger than $3 \mathrm{~m}^{2} \mathrm{~m}^{-2}$ were the biggest contributors to the non-linear relationship between AET and LAI in China. For these sites, they generally have higher annual precipitation and hence higher LAI compared with the sites located in the arid and semi-arid climate zones of China. However, their 
atmospheric evaporation demand is relatively lower than that of the arid and semi-arid sites. Thus, the balance between the geographic patterns of LAI (and MAP) and atmospheric evaporation demand shaped the non-linear spatial relationship between LAI and AET in China.

Based on the analyses above, we can infer the influencing mechanism of climate and vegetation on the spatial variation in AET of terrestrial ecosystems in China. The complex topography and monsoon climate in China shaped the spatial patterns of climatic factors including water, solar radiation and temperature, which jointly determined the geographic distribution of vegetation types and vegetation attributes (e.g., LAI) in turn. On this basis, climate and vegetation collectively controlled the spatial patterns of AET through their closely spatial coupling correlation, and hence shaped the distinct latitudinal and complex longitudinal patterns of AET in terrestrial ecosystems of China.

\section{Acknowledgements}

We sincerely thank two anonymous reviewers and XIAO Jingfeng for constructive comments and valuable suggestions. We acknowledge all the PIs of involved eddy-covariance flux sites for contributing valuable data. We also thank the agencies and institutions who supported the long-term measurements at these sites. We thank JUNG Martin, PIAO Shilong and ZENG Zhenzhong for providing global ET products. We acknowledge the database and technical support from Chinese Ecosystem Research Network, China Meteorological Administration and Oak Ridge National Laboratory.

\section{References}

Allen R G, Pereira L S, Raes D et al., 1998. Crop evapotranspiration: Guidelines for computing crop water requirements. FAO Irrigation and Drainage Paper No.56. Rome, FAO.

Baldocchi D, 2008. 'Breathing' of the terrestrial biosphere: Lessons learned from a global network of carbon dioxide flux measurement systems. Australian Journal of Botany, 56(1): 1-26.

Baldocchi D, Falge E, Gu L et al., 2001. FLUXNET: A new tool to study the temporal and spatial variability of ecosystem-scale carbon dioxide, water vapor, and energy flux densities. Bulletin of the American Meteorological Society, 82(11): 2415-2434.

Brümmer C, Black T A, Jassal R S et al., 2012. How climate and vegetation type influence evapotranspiration and water use efficiency in Canadian forest, peatland and grassland ecosystems. Agricultural and Forest Meteorology, 153: 14-30.

Budyko M, 1974. Climate and Life. translated from Russian by Miller D H. San Diego: Academic Press

Chen H, Lu W, Yan G et al., 2014. Typhoons exert significant but differential impacts on net ecosystem carbon exchange of subtropical mangrove forests in China. Biogeosciences, 11(19): 5323-5333.

Chen S P, Chen J Q, Lin G H et al., 2009. Energy balance and partition in Inner Mongolia steppe ecosystems with different land use types. Agricultural and Forest Meteorology, 149(11): 1800-1809.

Chen Z, Yu G, Ge J et al., 2013. Temperature and precipitation control of the spatial variation of terrestrial ecosystem carbon exchange in the Asian region. Agricultural and Forest Meteorology, 182/183: 266-276.

Cui S, 2007. Study on the $\mathrm{CO}_{2}$ flux of a larch plantation in NE China by the micrometeorological method [D]. Harbin: Northeast Forestry University. (in Chinese)

Ding R, Kang S, Vargas R et al., 2013. Multiscale spectral analysis of temporal variability in evapotranspiration over irrigated cropland in an arid region. Agricultural Water Management, 130: 79-89.

Dirmeyer P A, Gao X, Zhao M et al., 2006. GSWP-2: Multimodel analysis and implications for our perception of the land surface. Bulletin of the American Meteorological Society, 87(10): 1381-1397.

Dodds P E, Barton A, Meyer W S, 2005. A review of methods to estimate irrigated reference crop evapotranspira- 
tion across Australia. Technical Report 04/05, CRC for irrigation futures and CSIRO land and water. Adelaide, South Australia.

Dong G, Guo J X, Chen J Q et al., 2011. Effects of spring drought on carbon sequestration, evapotranspiration and water use efficiency in the Songnen meadow steppe in Northeast China. Ecohydrology, 4(2): 211-224.

Editorial Committee of Vegetation Map of China (ECVMC), 2007. Vegetation Map of the People's Republic of China (1:1000000). Beijing, China: Geology Publishing House. (in Chinese)

Falge E, Baldocchi D, Olson R et al., 2001. Gap filling strategies for long term energy flux data sets. Agricultural and Forest Meteorology, 107(1): 71-77.

Göckede M, Rebmann C, Foken T, 2004. A combination of quality assessment tools for eddy covariance measurements with footprint modelling for the characterisation of complex sites. Agricultural and Forest Meteorology, 127(3/4): 175-188.

Gu S, Tang Y H, Cui X Y et al., 2008. Characterizing evapotranspiration over a meadow ecosystem on the Qinghai-Tibetan Plateau. Journal of Geophysical Research, 113(D8): D08118.

Guo H, Noormets A, Zhao B et al., 2009. Tidal effects on net ecosystem exchange of carbon in an estuarine wetland. Agricultural and Forest Meteorology, 149(11): 1820-1828.

Guo L, 2010. The variations of water use efficiency and evapotranspiration over a plantation in sounthern part of hilly areas of North-China Master [D]. Beijing: Chinese Academy of Forestry. (in Chinese)

Han S, Huang L L, Wang Z Y et al., 2009. Ecosystem respiration and its controlling factors in the riparian wetland of Yangtze River. Acta Ecologica Sinica, 29(7): 22. (in Chinese)

Hao Y B, Wang Y F, Huang X Z et al., 2007. Seasonal and interannual variation in water vapor and energy exchange over a typical steppe in Inner Mongolia, China. Agricultural and Forest Meteorology, 146(1/2): 57-69.

He H L, Yu G R, Liu X A et al., 2004. Study on spatialization technology of terrestrial eco-information in China (II): Solar radiation. Journal of Natural Resources, 19(5): 679-687. (in Chinese)

Hutchinson M, 1995. Interpolating mean rainfall using thin plate smoothing splines. International Journal of Geographical Information Systems, 9(4): 385-403.

Jarvis P G, McNaughton K, 1986. Stomatal control of transpiration: Scaling up from leaf to region. Advances in Ecological Research, 15(1): 49.

Jung M, Reichstein M, Margolis H A et al., 2011. Global patterns of land-atmosphere fluxes of carbon dioxide, latent heat, and sensible heat derived from eddy covariance, satellite, and meteorological observations. Journal of Geophysical Research-Biogeosciences, 116(G3): G00J07. doi: 10.1029/2010JG001566.

Law B, Falge E, Gu L et al., 2002. Environmental controls over carbon dioxide and water vapor exchange of terrestrial vegetation. Agricultural and Forest Meteorology, 113(1-4): 97-120.

Lei H, Yang D, 2010. Interannual and seasonal variability in evapotranspiration and energy partitioning over an irrigated cropland in the North China Plain. Agricultural and Forest Meteorology, 150(4): 581-589.

Li J, Cai H, Cheng Q et al., 2012. Characterizing the evapotranspiration of a degraded grassland in the Sanjiangyuan Region of Qinghai province. Acta Prataculturae Sinica, 21(3): 223-233. (in Chinese)

Li S, Kang S, Zhang L et al., 2008. A comparison of three methods for determining vineyard evapotranspiration in the arid desert regions of Northwest China. Hydrological Processes, 22(23): 4554-4564.

Li X, Liang S, Yuan W et al., 2014. Estimation of evapotranspiration over the terrestrial ecosystems in China. Ecohydrology, 7(1): 139-149.

Li Z, Zhang Y, Wang S et al., 2010. Evapotranspiration of a tropical rain forest in Xishuangbanna, Southwest China. Hydrological Processes, 24(17): 2405-2416.

Lin E, Jiang H, Chen Y, 2013. Water vapor flux variation and net radiation for a Phyllostachys violascens stand in Taihuyuan. Journal of Zhejiang A\&F University, 30(3): 313-318. (in Chinese)

Lin Y, Wang G, Guo J et al., 2012. Quantifying evapotranspiration and its components in a coniferous subalpine forest in Southwest China. Hydrological Processes, 26(20): 3032-3040.

Liu H Z, Feng J W, 2012. Seasonal and interannual variations of evapotranspiration and energy exchange over different land surfaces in a semi-arid area of China. Journal of Applied Meteorology and Climatology, 51(10): 1875-1888.

Liu R, Li Y, Wang Q X, 2012. Variations in water and $\mathrm{CO}_{2}$ fluxes over a saline desert in western China. Hydrological Processes, 26(4): 513-522.

Liu S, Xu Z, Zhu Z et al., 2013b. Measurements of evapotranspiration from eddy-covariance systems and large aperture scintillometers in the Hai River Basin, China. Journal of Hydrology, 487: 24-38.

Liu Y, Zhou Y, Ju W et al., 2013a. Changes of evapotranspiration and water yield in China's terrestrial ecosystems during the period from 2000 to 2010. Hydrology and Earth System Sciences Discussions, 10(4): 5397-5456. 
McVicar T R, Jupp D L, 1998. The current and potential operational uses of remote sensing to aid decisions on drought exceptional circumstances in Australia: A review. Agricultural Systems, 57(3): 399-468.

$\mathrm{Mu} \mathrm{Q}$, Zhao M, Running S W, 2011. Improvements to a MODIS global terrestrial evapotranspiration algorithm. Remote Sensing of Environment, 115(8): 1781-1800.

Mueller B, Hirschi M, Jimenez C et al., 2013. Benchmark products for land evapotranspiration: LandFlux-EVAL multi-data set synthesis. Hydrology and Earth System Sciences, 17(10): 3707-3720.

Mueller B, Seneviratne S, Jimenez C et al., 2011. Evaluation of global observations-based evapotranspiration datasets and IPCC AR4 simulations. Geophysical Research Letters, 38(6): L06402.

Oki T, Kanae S, 2006. Global hydrological cycles and world water resources. Science, 313(5790): 1068-1972.

ORNL DAAC, 2014. MODIS subsetted land products, Collection 5. Available on-line [http://daac.ornl.gov/MODIS/modis.html] from ORNL DAAC, Oak Ridge, Tennessee, U.S.A. Accessed February $26,2015$.

Ouyang Z P, Mei X R, Li Y Z et al., 2013. Measurements of water dissipation and water use efficiency at the canopy level in a peach orchard. Agricultural Water Management, 129: 80-86.

Reichstein M, Falge E, Baldocchi D et al., 2005. On the separation of net ecosystem exchange into assimilation and ecosystem respiration: Review and improved algorithm. Global Change Biology 11(9): 1424-1439.

Shao C, Chen J, Li L, 2013. Grazing alters the biophysical regulation of carbon fluxes in a desert steppe. Environmental Research Letters, 8(2): 025012.

Shen Y, Zhang Y R, Scanlon B et al., 2013. Energy/water budgets and productivity of the typical croplands irrigated with groundwater and surface water in the North China Plain. Agricultural and Forest Meteorology, 181: 133-142.

Shi P, Sun X, Xu L et al., 2006. Net ecosystem $\mathrm{CO}_{2}$ exchange and controlling factors in a steppe-Kobresia meadow on the Tibetan Plateau. Science in China Series D: Earth Sciences, 49(Suppl.2): 207-218.

Shuttleworth W J, 2007. Putting the 'vap' into evaporation. Hydrology and Earth System Sciences, 11(1): $210-244$.

Shuttleworth W J, 2008. Evapotranspiration measurement methods. Southwest Hydrology, 7(1): 22-23.

Sun L, Song C, 2008. Evapotranspiration from a freshwater marsh in the Sanjiang Plain, Northeast China. Journal of Hydrology, 352(1/2): 202-210.

Tan Z H, Zhang Y P, Song Q H et al., 2011. Rubber plantations act as water pumps in tropical China. Geophysical Research Letters, 38: L24406.

Wang K C, Dickinson R E, 2012. A review of global terrestrial evapotranspiration: Observation, modeling, climatology, and climatic variability. Reviews of Geophysics, 50(2): RG2005.

Wang S, Yang Y, Luo Y et al., 2013. Spatial and seasonal variations in evapotranspiration over Canada's landmass. Hydrology and Earth System Sciences Discussions, 10(5): 6107-6151.

Wang W, Xu Z, Liu S et al., 2009. The characteristics of heat and water vapor fluxes over different surfaces in the Heihe River Basin. Advance in Earth Sciences, 24(7): 714-723. (in Chinese)

Wang W, Zhao Z, Kang W et al., 2011. Characteristics of latent heat flux over Cunninghamia lanceolata plantations in Huitong county. Journal of Central South University of Forestry \& Technology, 31(5): 192-197. (in Chinese)

Wang Y, Zhou G, Wang Y, 2008. Environmental effects on net ecosystem $\mathrm{CO}_{2}$ exchange at half-hour and month scales over Stipa krylovii steppe in northern China. Agricultural and Forest Meteorology, 148(5): 714-722.

Wang Z Y, 2008. Energy balance and water vapor flux of snail control and schistosomiasis prevention forests ecosystem in Yangtze River beach land [D] Beijing: Chinese Academy of Forestry. (in Chinese)

Webb E K, Pearman G I, Leuning R, 1980. Correction of flux measurements for density effects due to heat and water vapour transfer. Quarterly Journal of the Royal Meteorological Society, 106(447): 85-100.

Wen X F, Yu G R, Sun X M et al., 2006. Soil moisture effect on the temperature dependence of ecosystem respiration in a subtropical Pinus plantation of southeastern China. Agricultural and Forest Meteorology, 137(3/4): $166-175$.

Williams C A, Reichstein M, Buchmann N et al., 2012. Climate and vegetation controls on the surface water balance: Synthesis of evapotranspiration measured across a global network of flux towers. Water Resources Research, 48(6): W06523.

Wilske B, Lu N, Wei L et al., 2009. Poplar plantation has the potential to alter the water balance in semiarid Inner Mongolia. Journal of Environmental Management, 90(8): 2762-2770.

Wilson K B, Baldocchi D D, 2000. Seasonal and interannual variability of energy fluxes over a broadleaved temperate deciduous forest in North America. Agricultural and Forest Meteorology, 100(1): 1-18.

Wu J, Chen J, Wu H et al., 2013. Comparative study of evapotranspiration in an alpine meadow in the upper reach of Shulehe River Basin. Scientia Geographica Sinica, 33(1): 97-103. (in Chinese) 
Xiao J, Sun G, Chen J et al., 2013. Carbon fluxes, evapotranspiration, and water use efficiency of terrestrial ecosystems in China. Agricultural and Forest Meteorology, 182: 76-90.

Yan G Y, 2012. Tidal influence on energy balance and evapotranspiration of mangrove ecosystem in subtropical area [D]. Xiamen: Xiamen University. (in Chinese)

Yan H, Wang S Q, Billesbach D et al., 2012. Global estimation of evapotranspiration using a leaf area index-based surface energy and water balance model. Remote Sensing of Environment, 124: 581-595.

Yang D, Sun F, Liu Z et al., 2007. Analyzing spatial and temporal variability of annual water-energy balance in nonhumid regions of China using the Budyko hypothesis. Water Resources Research, 43(4): W04426.

Yang F, Zhang Q, Wang R et al., 2013. Characteristics of evapotranspiration and crop coefficient of agroecosystems in semi-arid area of Loess Plateau, Northwest China. Chinese Journal of Applied Ecology, 24(5): 1209-1214. (in Chinese)

Yu G, Chen Z, Piao S et al., 2014. High carbon dioxide uptake by subtropical forest ecosystems in the East Asian monsoon region. Proceedings of the National Academy of Sciences, 111(13): 4910-4915.

Yu G R, Sun X M, 2006. Principles of Flux Measurements in Terrestrial Ecosystems. Beijing: Higher Education Press. (in Chinese)

Yu G R, Wen X F, Sun X M et al., 2006. Overview of ChinaFLUX and evaluation of its eddy covariance measurement. Agricultural and Forest Meteorology, 137(3): 125-137.

Yu G R, Zhu X J, Fu Y L et al., 2013. Spatial patterns and climate drivers of carbon fluxes in terrestrial ecosystems of China. Global Change Biology, 19(3): 798-810.

Yuan W P, Liu S G, Yu G R et al., 2010. Global estimates of evapotranspiration and gross primary production based on MODIS and global meteorology data. Remote Sensing of Environment, 114(7): 1416-1431.

Zeng Z, Wang T, Zhou F et al., 2014. A worldwide analysis of spatiotemporal changes in water balance-based evapotranspiration from 1982 to 2009. Journal of Geophysical Research: Atmospheres, 119(3): 1186-1202.

Zhang F, Zhou G S, Wang Y et al., 2012. Evapotranspiration and crop coefficient for a temperate desert steppe ecosystem using eddy covariance in Inner Mongolia, China. Hydrological Processes, 26(3): 379-386.

Zhang J H, Han S J, Yu G R 2006. Seasonal variation in carbon dioxide exchange over a 200-year-old Chinese broad-leaved Korean pine mixed forest. Agricultural and Forest Meteorology, 137(3/4): 150-165.

Zhang K, Kimball J S, Nemani R R et al., 2010. A continuous satellite-derived global record of land surface evapotranspiration from 1983 to 2006. Water Resources Research, 46(9): W09522.

Zhang Y, 2010. Energy and water budget of a poplar plantation in suburban Beijing [D]. Beijing: Beijing Forestry University. (in Chinese)

Zhang Y, Shen Y, Xu X et al., 2013. Characteristics of the water-energy-carbon fluxes of irrigated pear (Pyrus bretschneideri Rehd) orchards in the North China Plain. Agricultural Water Management, 128: 140-148.

Zhao F H, Yu G R, Li S G et al., 2007. Canopy water use efficiency of winter wheat in the North China Plain. Agricultural Water Management, 93(3): 99-108.

Zhao L W, Zhao W Z, 2014. Evapotranspiration of an oasis-desert transition zone in the middle stream of Heihe River, Northwest China. Journal of Arid Land, 6(5): 529-539.

Zhao X, Huang Y, Jia Z et al., 2008. Effects of the conversion of marshland to cropland on water and energy exchanges in northeastern China. Journal of Hydrology, 355(1-4): 181-191.

Zheng H, Wang Q F, Zhu X J et al., 2014. Hysteresis responses of evapotranspiration to meteorological factors at a diel timescale: patterns and causes. PLoS One, 9(6): e98857.

Zhou G S, Wang Y, Zhou L, 2010. Dynamics of carbon budgets in typical corn and rice ecosystems in Liaohe delta. In: Proceedings of Low Carbon Agriculture Symposium, 265-271. (in Chinese)

Zhou L, Zhou G, Liu S et al., 2010. Seasonal contribution and interannual variation of evapotranspiration over a reed marsh (Phragmites australis) in Northeast China from 3-year eddy covariance data. Hydrological Processes, 24(8): 1039-1047.

Zhou S, Wang J, Liu J et al., 2012. Evapotranspiration of a drip-irrigated, film-mulched cotton field in northern Xinjiang, China. Hydrological Processes, 26(8): 1169-1178.

Zhou X, Zhu Q, Sun Z et al., 2002. Preliminary study on regionalization desertification climate in China. Journal of Natural Disasters, 11(2): 125-131. (in Chinese)

Zhu G, Lu L, Su Y et al., 2014. Energy flux partitioning and evapotranspiration in a sub-alpine spruce forest ecosystem. Hydrological Processes, 28(19): 5093-5104.

Zhu X, Yu G, Wang Q et al., 2012. Instrument heating correction effect on estimation of ecosystem carbon and water fluxes. Chinese Journal of Ecology, 31(2): 487-493. (in Chinese) 